\title{
Effect of Heat Assisted Bath Sonication on the Mechanical and Thermal Deformation Behaviours of Graphene Nanoplatelets Filled Epoxy Polymer Composites
}

\author{
Jin-Luen Phua, ${ }^{1}$ Pei-Leng Teh, ${ }^{1}$ Supri Abdul Ghani, ${ }^{2}$ and Cheow-Keat Yeoh ${ }^{1}$ \\ ${ }^{1}$ School of Materials Engineering, Universiti Malaysia Perlis, Kompleks Taman Muhibbah, Jejawi 2, 02600 Arau, Perlis, Malaysia \\ ${ }^{2}$ Faculty of Engineering, Universiti Malaysia Perlis, Main Campus, Pauh Putra, 02600 Perlis, Malaysia \\ Correspondence should be addressed to Jin-Luen Phua; jlphua@hotmail.com
}

Received 30 December 2015; Accepted 6 March 2016

Academic Editor: Laurent Billon

Copyright ( 92016 Jin-Luen Phua et al. This is an open access article distributed under the Creative Commons Attribution License, which permits unrestricted use, distribution, and reproduction in any medium, provided the original work is properly cited.

Graphene nanoplatelets (GNP) filled epoxy composites ranged from 0.2 to 5 vol.\% were prepared in this study using simple heat assisted bath sonication for better GNP dispersion and exfoliation. The effects of GNP filler loading via heat assisted bath sonication on the mechanical properties and thermal deformation behaviour were investigated. Improvements on flexural strength and fracture toughness up to 0.4 vol.\% filler loading were recorded. Further addition of GNP filler loading shows a deteriorating behaviour on the mechanical properties on the composites. The bulk electrical conductivity of the epoxy composites is greatly improved with the addition of GNP filler loading up to 1 vol.\%. The thermal expansion of epoxy composites is reduced with the addition of GNP; however poor thermal stability of the composites is observed.

\section{Introduction}

Graphene, the wonder material for the past decade, has drawn the attention of material engineers and scientists, for its remarkable attributes. From structural point of view, graphene is a single-layer carbon atom arranged in hexagonal lattice, at which the interaction between carbon atoms is made through strong sigma bonds, via the overlap of inplane $\mathrm{sp}^{2}$ orbitals. The $2 \mathrm{D}$ honeycomb structure of this nanomaterial was demonstrated to possess excellent mechanical properties, good electrical and in-plane thermal conductivity [1-3]. Graphene nanoplatelets (GNP) consisted of the stacked layer of graphene sheets which are highly used as filler in the study of polymer composites [4-8]. The geometry structure of GNP, with particle size of nanoscale thickness and micron scale lateral surface area, which allow a high surface contact area, is embedded in polymer matrix at low filler loading, hence improving the properties of the polymer matrix, without sacrificing any intrinsic properties.

Epoxy, as an important class of polymer resin, which is widely utilized in different application, is honest prospect to consider within the issue of incorporation of GNP. Epoxy resin is mainly used in a specific application, such as adhesives, aerospace industry for outer body part, and insulating material for corrosion application [9]. However, poor electrical and thermal conductivity with high thermal expansion coefficient (CTE) upon rising temperature are the main weaknesses of epoxy. These weaknesses are especially crucial, where epoxy resin is used as organic substrate in electronic packaging application. The wide difference of CTE value between epoxy and silicon upon rising temperature can cause failure and deformation where heat is a constant factor [10-12].

The CTE of epoxy can be greatly reduced with the incorporation of high thermal conductive fillers, such as metal powder, carbon black, and other fillers, but generally required high filler loading, which leads to another obstacle, viscosity increment on the polymer matrix, which resulted in difficulties during processing. Gathering from previous studies, the filler loading required to give tuneable effect on the electrical and thermal conductivity of epoxy resin will require $10-20$ vol.\% of filler loading $[13,14]$, depending on several 
factors, including processing methodology, particle size of filler [15-18], particle distribution [19], and particle aspect ratio $[20,21]$. Nanofillers, such as graphene nanoplatelets, are one of the promising steps to greatly reduce the filler loading, down to $0.01-1$ vol.\%, as reported previously, due to its $2 \mathrm{D}$ geometry and particle size, hence greatly reducing the percolation threshold $[6,22]$ and thermal conductivity [2325].

The bottleneck of using nanosize filler is that it required a proper dispersion process, in order to achieve a good dispersion into the polymer matrix, as well as a good interfacial interaction between the filler and polymer matrix. This specific step is hardly achieved under direct mixing method and required specific tools and/or solvents in order to tailor the desired result. This is due to flat shape of these fillers, which tend to aggregate under normal condition, owing to the strong Van der Waals forces [26]. A commercial type of GNP was used here, to prepare the epoxy nanocomposites, and the effects of GNP filler loading incorporated in epoxy were investigated.

In this study, the usage of sophisticated equipment or chemical-assisted exfoliation processes for graphene dispersion in polymer matrix are avoided for ease of processing and environmental preservation. In order to achieve a homogeneous dispersion of GNP into epoxy resin, a sonication process was used after direct mixing of GNP into epoxy resin. Heat assisted bath sonication was used in this process, where temperature is used to reduce the viscosity of epoxy resin in order to help the dispersion process of GNP into epoxy resin. The GNP filled epoxy composites were prepared with the addition of $0.2,0.4,0.6,0.8,1,3$, and 5 vol. $\%$ filler loading. We investigated the effects of GNP filler loading on flexural, fracture toughness, electrical, CTE, and thermal stability properties, as compared to the control pure epoxy. GNP filler loading above 5 vol.\% was not studied in this work because of the difficulty of processing due to the increased viscosity.

\section{Experimental}

2.1. Materials. Graphene nanoplatelets (GNP), grade 0540DX, which come in granular form, with thickness $1-5 \mathrm{~nm}$, average particle diameter less than $2 \mu \mathrm{m}$, surface area $750 \mathrm{~m}^{2} / \mathrm{g}$, and $99 \%$ carbon content, were purchased from Skyspring Nanomaterials, Inc. Epoxy resin and hardener used in this research were clear epoxy resin DER 331, density $1.16 \mathrm{~g} / \mathrm{cm}^{3}$, and epoxy hardener, which both were supplied by Euro Chemo-Pharma Sdn. Bhd. All the materials were used as received without further modifications.

2.2. Sample Preparation. GNP filled epoxy composites with different filler loading were prepared followed by $0.2,0.4$, $0.6,0.8,1,3$, and 5 vol.\% filler loading. Weighted amount of epoxy resin was directly mixed with GNP powders for 5 minutes at room temperature and followed by 30 minutes of bath sonication at $60^{\circ} \mathrm{C}$. After sonication, continuous stirring process was done until the resin cooled down to room temperature. This is to prevent the reagglomeration of GNP after sonication process during cooling. $60 \mathrm{phr}$ of hardener was added into the epoxy resin and stirred for 10 minutes. The epoxy resin was casted into a mold and degassing process was done using a vacuum oven for 30 minutes. The epoxy resin was cured at $100^{\circ} \mathrm{C}$ for 1 hour and, after that, cut into desired dimension for testing purpose.

2.3. Characterization. Fourier-transform infrared (FTIR) spectroscopy was carried out via Perkin Elmer Model Spectrum 65 USA instrument and scanned within the wavelength range of $4000-500 \mathrm{~cm}^{-1}$. Flexural strength and modulus were determined using Instron 5569 Universal Testing Machine (UTM). The testing was done according to ASTM D790 with 3-point bending at room temperature, with crosshead motion speed of $2.38 \mathrm{~mm} \cdot \mathrm{min}^{-1}$. Fracture toughness was done according to ISO 13586, using Instron 5569 Universal Testing Machine (UTM). The single-edge notched samples were cut and subjected to static tensile loading (SEN-T), with loading speed of $1 \mathrm{~mm} \cdot \mathrm{min}^{-1}$ at room temperature. The samples notching was done by sawing and sharpening with a razor blade. Bulk electrical resistivity and conductivity were measured using Fluke 8845A/8846A 6.5 digit precision multimeter. Resistance was measured during the testing and bulk conductivity of each sample was calculated according to

$$
\begin{aligned}
\text { Bulk resistivity } & =\frac{R \times A}{h}, \\
\text { Bulk conductivity } & =\frac{1}{\text { bulk resistivity }},
\end{aligned}
$$

where $R$ is resistance of the measured samples, $A$ is crosssectional area of the measured samples, and $h$ is height of the measured samples.

Thermal stability of the samples was measured using PerkinElmer model TGA7. Samples weighing 5-10 mg were heated from $30^{\circ} \mathrm{C}$ to $800^{\circ} \mathrm{C}$ under nitrogen gas flow with heating rate of $10^{\circ} \mathrm{C} \cdot \mathrm{min}^{-1}$. The thermal expansion coefficient and glass transition temperature $\left(T_{g}\right)$ were measured using Linseis L75 Platinum Series. Samples were heated from $30^{\circ} \mathrm{C}$ to $250^{\circ} \mathrm{C}$, with heating rate of $5^{\circ} \mathrm{C} \cdot \mathrm{min}^{-1}$, and the thermal expansion coefficient of the samples was calculated based on

$$
\alpha=\frac{1}{L} \frac{d L}{d T},
$$

where $L$ is measured length of the samples $(\mathrm{mm})$ and $d L / d T$ is change of the length of the sample per unit change in temperature.

\section{Results and Discussion}

3.1. Characterization of GNP. In order to understand the influence of GNP incorporation into epoxy matrix, the characterizations towards the raw GNP powder were done. The SEM micrograph of GNP powder is shown in Figure 1(a). As seen, the GNP powder appeared in granular form for ease of shipment and handling. The FTIR of raw GNP powder is presented in Figure 1(b). Strong adsorption peak is observed at $3434 \mathrm{~cm}^{-1}$, attributed to the $\mathrm{O}-\mathrm{H}$ stretching of carboxylic and phenolic group. Two peaks located at 


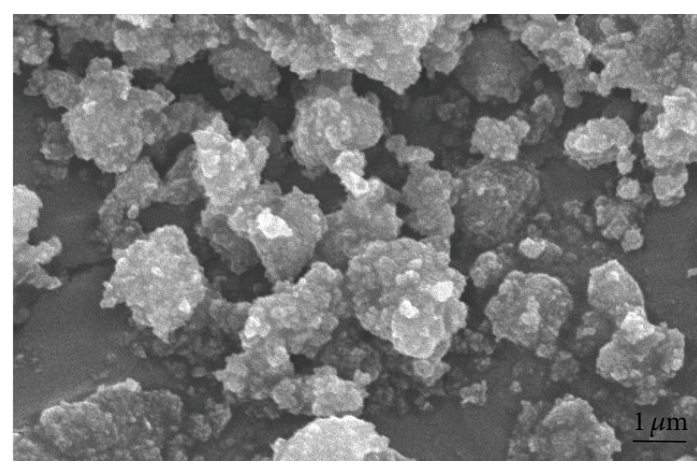

(a)

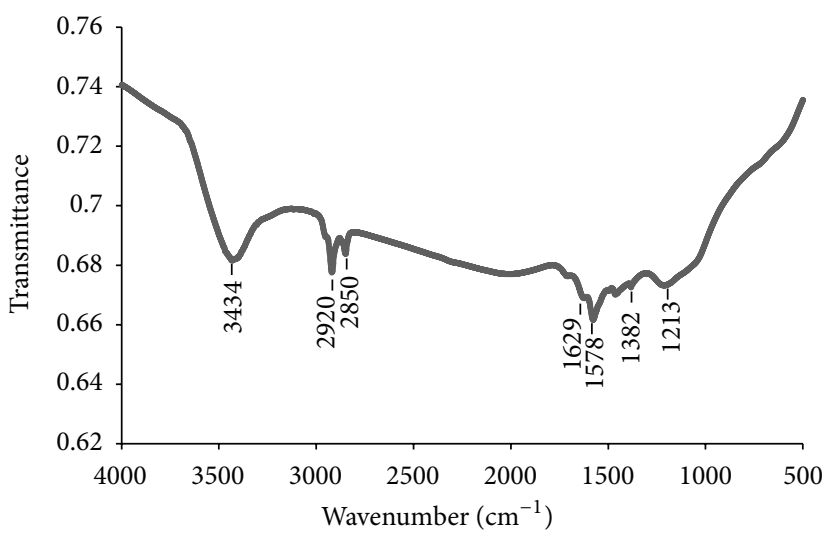

(b)

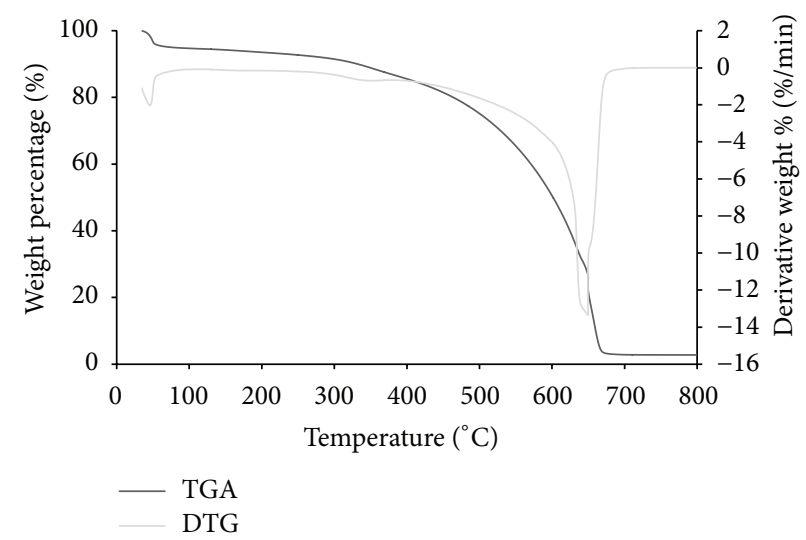

(c)

Figure 1: (a) SEM micrograph of GNP powder; (b) FTIR spectra; and (c) TGA and DTG curve of raw GNP.

wavelength of $2920 \mathrm{~cm}^{-1}$ and $2850 \mathrm{~cm}^{-1}$ are believed to be the aliphatic compound found on the surface of GNP. The characteristic adsorption band corresponding to $\mathrm{C}=\mathrm{O}$ stretching of ketone, lactone, and carboxyl group appears at $1629 \mathrm{~cm}^{-1}$ and $1578 \mathrm{~cm}^{-1}$, respectively. Peak at $1382 \mathrm{~cm}^{-1}$ shows the stretching vibration of $\mathrm{C}-\mathrm{OH}$. Figure 1(c) shows the TGA plot of raw GNP powder. From the figure, the degradation behaviour of raw GNP shows one-step degradation, where the major degradation happened at $450^{\circ} \mathrm{C}-$ $650^{\circ} \mathrm{C}$, which is further proven via the DTG curve. According to Wang et al. [22], the decomposition of oxygen-containing functional group on GNP happened at temperature ranged from $250^{\circ} \mathrm{C}$ to $350^{\circ} \mathrm{C}$, while thermal degradation of GNP structure happened at $450^{\circ} \mathrm{C}-800^{\circ} \mathrm{C}$.

3.2. Mechanical Properties of GNP Filled Epoxy Composites. Flexural properties of GNP filled epoxy composites were shown in Figures 2 and 3, which represent the flexural strength and flexural modulus, respectively. At 0 vol.\% GNP filler loading, the flexural strength of epoxy is recorded at $58.23 \pm 0.3 \mathrm{MPa}$ and flexural modulus at $2055.85 \pm$ $40 \mathrm{MPa}$. With addition of minimum GNP filler loading at 0.2 vol.\%, the flexural strength of GNP filled epoxy composites increased almost $40 \%$, recorded at $81.20 \pm 0.8 \mathrm{MPa}$, while the flexural modulus increased up to $16.4 \%$, recorded at $2392.48 \pm 49 \mathrm{MPa}$. An increase of GNP filler loading from
0.2 to 0.4 vol. $\%$ induces sharp increase of flexural modulus; however, with further addition of GNP content, the changes were not significant, as shown in Figure 3. With the continuous addition of GNP filler loading, from 0.4 to 5 vol.\%, no significant increment nor decrement was observed for flexural strength of GNP filled epoxy composites; however, based on the moving average on the flexural strength versus the GNP filler loading, a trend of decrement on the composites strength is observed starting from 0.4 vol.\% GNP filler loading. This result is further confirmed with the fracture toughness of GNP filled epoxy composites result in Figure 4, where a similar trend is observed as the GNP filler loading increased. The fracture toughness was increased nearly to $150 \%$ with addition of 0.2 vol. $\%$ of GNP filler loading but started to decrease drastically with 0.8 vol.\% of GNP filler loading onwards.

The stiffness of the GNP filled epoxy composites increased as the GNP filler loading increased, as it was mentioned previously as flexural modulus. Large modulus of graphene is the main reason for the stiffen composites [8]. Besides that, the uniform stress transfer from matrix to filler and segmentation immobilization caused by the interaction of polymer chains and filler surface also contributed to such phenomenon. The mechanical behaviour of the thermosetting resin with the addition of GNP shows promising enhancement with the addition of low GNP content but starts 




FIGURE 2: Flexural strength of GNP filled epoxy composites.

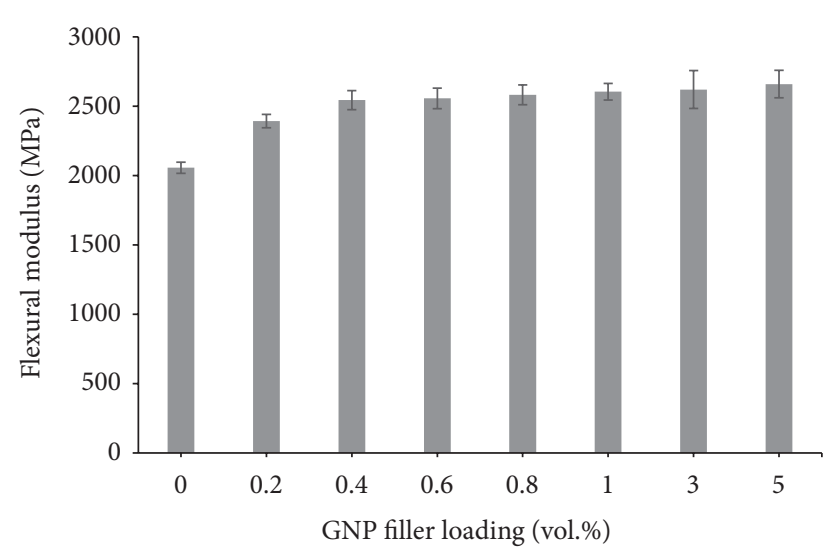

FIGURE 3: Flexural modulus of GNP filled epoxy composites.

to deteriorate when the filler content increased by more than 0.4 vol.\%, which is a limitation where a higher GNP content is needed in order to tailor the high electrical and thermal conductivity properties. One of the main reasons for this phenomenon to occur is the poor interaction between the GNP and the epoxy matrix; hence weak interface between filler and matrix rises. This weak interface of filler and matrix can act as stress concentrator, where load could not transfer evenly from matrix to filler or filler to matrix, causing the deterioration of mechanical properties of the GNP filled epoxy composites at higher filler loading.

Besides that, the deterioration behaviour of mechanical properties of nanofiller reinforced polymer composites is due to the dispersion problem of nanofiller in polymer matrix, which is common phenomenon. The weak interfacial interaction between filler and matrix further decreases the degree of dispersion when the filler loading increased, causing the filler to reaggregate or reagglomerate after mixing process. Besides that, due to its 2D geometry, strong Van der Waals force occurs between the graphene sheets, hence further inhibiting the dispersion of the nanofillers in polymer matrix. The failure of uniform dispersion of GNP in polymer matrix as reported by Prolongo et al. [4] also resulted in increased modulus but decreased mechanical strength.

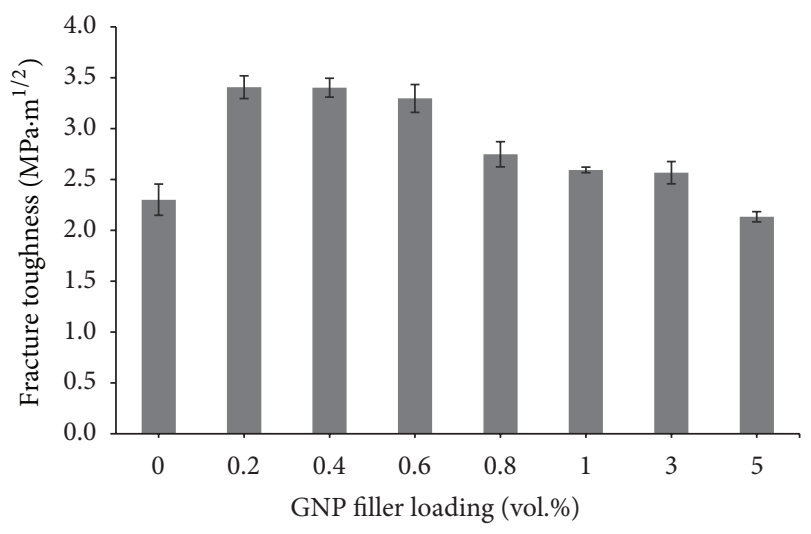

FIGURE 4: Fracture toughness of GNP filled epoxy composites.

In order to further investigate the dispersion state of GNP in epoxy, the fracture surface of the composites with GNP filler loading at $0.4,1$, and 5 vol.\% was inspected under SEM characterization. From Figure 5, at lower magnification, in contrast to the glassy, smooth surface of epoxy, the GNP filled epoxy composites (Figure 5(a)) are rough and rivers of crack line can be seen on the fracture surface. Besides that, the deformation mechanism of GNP filled epoxy composites is different to pure epoxy as observed from the SEM micrograph, where crack deviation happened, with numerous crack lines growing in different direction and plane. It is believed that the $2 \mathrm{D}$ geometry structure of graphene effectively interrupted and diverted the crack propagation and, hence, influenced the deformation and fracture mechanism. This phenomenon happened as interaction between GNP and epoxy matrix that helped the load transfer process from matrix to filler, where increase of crack lines and crack deviation is observed, indicating the deformation mechanism required more energy for failure to occur and led to the improvement on both flexural strength and fracture toughness. As the GNP filler loading increased from 0.4 to 5 vol.\%, the density of the crack lines reduced, indicating lower energy needed for deformation to happen due to the high filler loading of GNP. This can be further explained by the poor interfacial interaction between GNP and epoxy matrix, which leads to flexural strength decrease as the GNP filler loading increased. At higher magnification, the agglomeration of GNP is observed, and the agglomeration grows larger as the GNP filler loading increased.

\subsection{Bulk Electrical Conductivity of GNP Filled Epoxy Com-} posites. The bulk electrical resistivity and conductivity of the GNP filled epoxy composites were measured and the results are shown in Figure 6. The percolation threshold of conductive filler filled polymer composites is always defined as the minimum filler content needed to change the electrical insulating properties of polymer to become semiconductor/conductor. From the figure, the addition of GNP below 1 vol.\% scarcely shows any effect on the electrical conductivity of the composites. However, at 1 vol.\% of GNP filler loading, sudden change on the electrical conductivity properties of the 


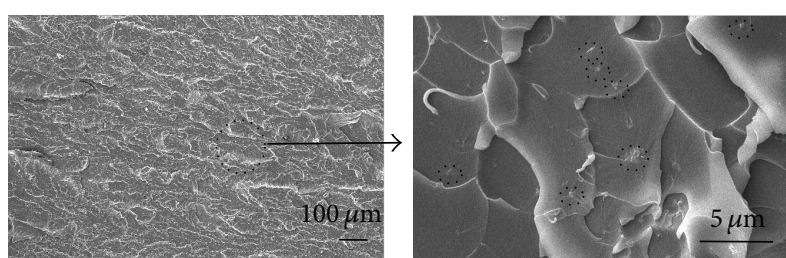

(a)

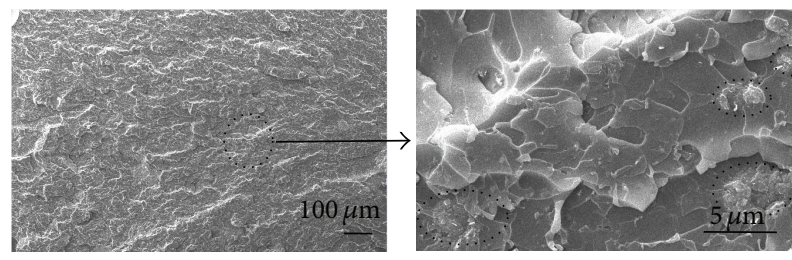

(b)


(c)

FIGURE 5: SEM micrographs of flexural fracture surface of GNP filled epoxy composites at 0.4 (a), 1 (b), and 5 vol.\% (c).

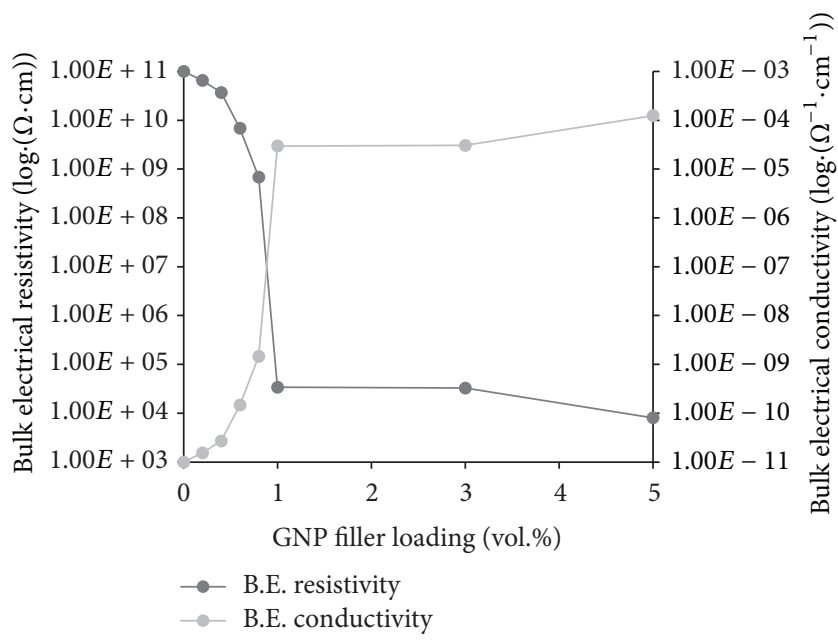

FIGURE 6: Bulk electrical resistivity and conductivity of GNP filled epoxy composites.

composites can be observed, where the electrical conductivity of the composites increased by several orders of magnitude. Higher GNP filler loading above 1 vol.\% is investigated, in order to determine the percolation threshold of the GNP filler loading. With higher GNP filler loading at 3 and $5 \mathrm{vol} . \%$, insignificant increment of electrical conductivity of the composites is observed.

This phenomenon can be explained through the understanding of the physical contact of the conductive filler embedded among the polymer matrix. When the filler loading is below percolation, the physical contact between the conductive fillers is limited; hence, the formation of conductive networks is greatly inhibited. At the point of percolation threshold reached, the filler content used is enough for the filler to make a good physical contact with each other, hence building up a conductive network through the polymer matrix and greatly increasing the electrical conductivity of the composites. Unfortunately, with further addition of GNP filler loading, the physical contact between the fillers is saturated and the formation of conductive networks could not be further increased; hence no significant improvement on electrical conductivity can be observed.

Table 1 summarized the comparison study on the electrical conductivity in the current study and previous works [27-29]. The particle size of GNP (diameter and thickness), dispersion method, solvent used for dispersion aid, and electrical properties (maximum electrical conductivity and filler loading at maximum electrical conductivity) are listed in the table. From our study, at 1 vol.\% GNP filler loading, the electrical conductivity measured is $2.9 \times 10^{-3} \mathrm{~S} / \mathrm{m}$, which is higher than those previous works, except [27]. The electrical properties of filled composites can be governed by many factors, which included processing method, filler loading, particles shape and size, conductivity of matrix and filler, and degree of dispersion of filler in matrix. Comparing between the dispersion methods of GNP into epoxy resin, present study shows a simple but promising processing method, where similar reading of electrical conductivity is achieved compared to previous studies without the aid of machining or solvent.

3.4. Thermal Properties of GNP Filled Epoxy Composites. The thermal expansion coefficient (CTE) of GNP filled epoxy composites was shown in Figure 7. From the measurement, the CTE of GNP filled epoxy composites were calculated before and after the glass transition temperature $\left(T_{g}\right)$, and the main concern is focused on the CTE value before $T_{g}$, where most of the mechanical properties of epoxy are lost after $T_{g}$. Before $T_{g}$, the pure epoxy with CTE value of $70 \times 10^{-6} \cdot \mathrm{C}^{-1}$ is measured and as much as $20 \%$ reduction in the CTE value of epoxy was recorded with 0.2 vol. $\%$ of GNP filler loading. The reduction of CTE value before $T_{g}$ becomes insignificant after 0.6 vol.\% of GNP filler loading.

For the CTE value after $T_{g}$, the CTE values are expected to be higher as the glassy state of epoxy becomes rubbery and crosslink density plays an important role in CTE value after $T_{g}$. However, due to limitation of equipment, crosslink density of GNP filled epoxy composites was not studied here. Similar trend of CTE is observed after $T_{g}$, where tremendous drop in CTE value as compared to pure epoxy was observed with GNP filler loading as low as $0.2 \mathrm{vol}$.\%. However, upon $1 \mathrm{vol} . \%$, the increment of CTE is observed. This phenomenon can be explained by the lower $T_{g}$ recorded starting from 1 vol.\% of GNP filler loading.

$T_{g}$ of GNP filled epoxy composites and pure epoxy was determined from the thermal expansion curve, where $T_{g}$ is measured at the cross-point of two different slopes. Two significant slopes can be observed where the expansion is 
TABLE 1: Comparison study on the electrical conductivity of GNP filled epoxy system, with different particles size and dispersion method.

\begin{tabular}{|c|c|c|c|c|c|}
\hline $\begin{array}{l}\text { Filler particle size } \\
\text { (diameter/thickness) }\end{array}$ & $\begin{array}{l}\text { Dispersion method of } \\
\text { GNP into epoxy }\end{array}$ & Solution & $\begin{array}{l}\text { Maximum } \\
\text { electrical } \\
\text { conductivity } \\
(\mathrm{S} / \mathrm{m})\end{array}$ & $\begin{array}{c}\text { Filler loading at } \\
\text { maximum electrical } \\
\text { conductivity (vol.\% or } \\
\text { wt.\%) }\end{array}$ & References \\
\hline$<2 \mu \mathrm{m} / 1-5 \mathrm{~nm}$ & $\begin{array}{l}\text { Heat assisted bath } \\
\text { sonication }\end{array}$ & None & $2.9 \times 10^{-3}$ & 1 vol.\%/1.96 wt.\% & Current study \\
\hline $15 \mu \mathrm{m} / 5-10 \mathrm{~nm}$ & Tip sonication & None & $6 \times 10^{-3}$ & 0.6 vol. $\% / 1.16$ wt. $\%$ & [27] \\
\hline $20-50 \mu \mathrm{m} / 12-15 \mathrm{~nm}$ & Three-roll mill & None & $2 \times 10^{-3}$ & 0.5 wt. $\%$ & {$[28]$} \\
\hline $20-50 \mu \mathrm{m} / 12-15 \mathrm{~nm}$ & $\begin{array}{l}\text { Sonication, high speed } \\
\text { shear mixing }\end{array}$ & Ethyl acetate & $1 \times 10^{-6}$ & 1 wt.\% & [28] \\
\hline $25 \mu \mathrm{m} /<10 \mathrm{~nm}$ & Tip sonication & Chloroform & $9.6 \times 10^{-4}$ & 3 wt.\% & [29] \\
\hline $25 \mu \mathrm{m} /<10 \mathrm{~nm}$ & Tip sonication & Tetrahydrofuran & $5.8 \times 10^{-4}$ & 3 wt. $\%$ & [29] \\
\hline
\end{tabular}

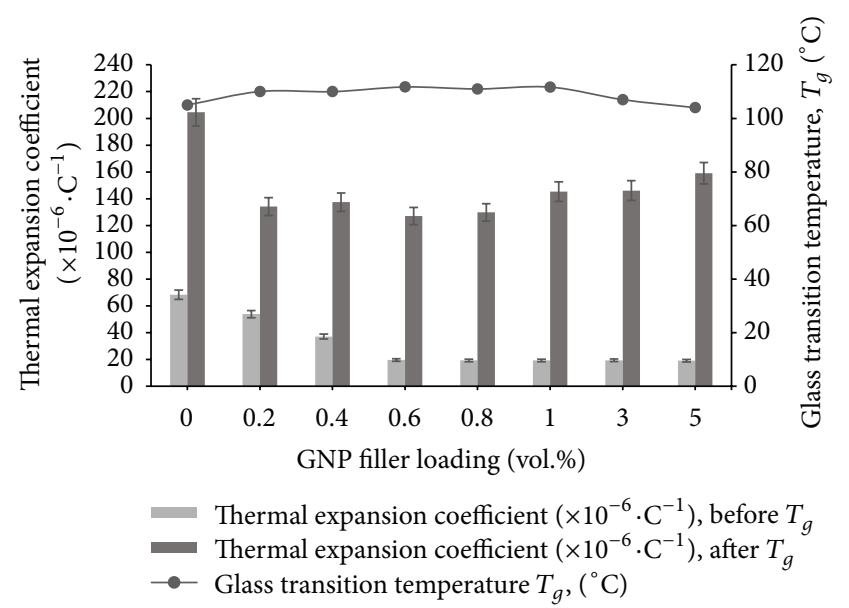

FIgURE 7: Thermal expansion coefficient of GNP filled epoxy composites.

slowed before $T_{g}$ and dramatically increased after $T_{g}$. From the results, $T_{g}$ of pure epoxy is recorded at $105^{\circ} \mathrm{C}$, and $T_{g}$ increased steadily with GNP filler loading from 0.2 to 1 vol. $\%$ and starts to decrease upon 1 vol.\% of GNP filler loading. This phenomenon can be explained by the effect of GNP bundling tendency and viscosity of matrix increment upon high filler loading before curing [30]. The curing behaviour of epoxy can be divided into two stages, where chemical reaction occurs and is followed by diffusion controlled of which gelation and vitrification happened.

The introduction of high filler loading of GNP to epoxy resin has been found to increase the viscosity of the resin; thus the second stage of epoxy curing is expected to occur earlier as compared to pure epoxy due to higher viscosity level. Lower or comparable cure degree of the composites as compared to pure epoxy is expected due to the advanced curing obtained in the early stage. Lower cure degree can lead to lower $T_{g}$. The lower cure degree could be counterbalanced by the restricted mobility of polymer chains with the addition of filler and hence provide higher $T_{g}$ level. However, the aspect ratio and good dispersion state of GNP in epoxy are hardly achieved upon high filler loading, where agglomeration and poor degree of dispersion are observed.
The thermal stability of GNP filled epoxy composites is shown in Figures 8 and 9, respectively. Thermal stability of pure epoxy and GNP filled epoxy composites at different filler loading is shown in Figure 8, where no significant improvement on thermal stability can be observed. Overall, the decomposition behaviours of GNP filled epoxy composites are similar to pure epoxy, where a major decomposition occurs at temperature of $350^{\circ} \mathrm{C}-450^{\circ} \mathrm{C}$. This can be further proven by the DTG curves in Figure 9, where high rate of major weight loss happened in the same range of temperature.

In Table 2, the remaining weight percentage (\%) of GNP filled epoxy composites at different temperatures as compared to pure epoxy was shown. In the table, the decomposition behaviour of the composites is categorised as 1st weight loss region (before major decomposition), 2nd weight loss region (where major decomposition happened), and 3rd weight loss region (after major decomposition) to have a better understanding of the effect of GNP filler loading towards the decomposition of epoxy composites. The 1st weight loss region can most probably be attributed to the moisture and volatile contents, which resulted from the incomplete curing of the epoxy resin; 2nd weight loss region can evidently be attributed to degradation of epoxy itself, while 3rd weight loss region is attributed to the char formation of the remaining degradation products.

From Table 2, the remaining weight percentage of GNP filled epoxy composites at $350^{\circ} \mathrm{C}$ shows a lower or similar value as compared to pure epoxy. This indicated the incorporation of GNP into epoxy resin did not improve the thermal stability of the composites. GNP is well known for its high thermal conductivity properties, but, in this case, the poor interfacial interaction between epoxy and GNP can greatly increase the thermal boundary resistance, hence hindering the thermal flow from matrix to filler or filler to matrix. Upon heating, the GNP did not function well as a good thermal conductor, where the heat is focused and did not dissipate through the composites, which resulted in poor thermal stability.

\section{Conclusion}

In this study, the effect of GNP filler loading on the properties of the epoxy composites is investigated. The incorporation 
TABLE 2: Remaining weight percentage (\%) of GNP filled epoxy composites at different temperature $\left({ }^{\circ} \mathrm{C}\right)$.

\begin{tabular}{lcccccccccc}
\hline \multirow{2}{*}{ No. } & \multirow{2}{*}{ Composition } & \multicolumn{2}{c}{ 1st weight loss region } & \multicolumn{3}{c}{ 2nd weight loss region } & \multicolumn{4}{c}{ 3rd weight loss region } \\
& & $100^{\circ} \mathrm{C}$ & $250^{\circ} \mathrm{C}$ & $350^{\circ} \mathrm{C}$ & $400^{\circ} \mathrm{C}$ & $475^{\circ} \mathrm{C}$ & $550^{\circ} \mathrm{C}$ & $575^{\circ} \mathrm{C}$ & $600^{\circ} \mathrm{C}$ & $800^{\circ} \mathrm{C}$ \\
\hline 1 & Pure epoxy & 99.5 & 88.5 & 80.8 & 28.1 & 11 & 9 & 8.7 & 8.5 & 8.1 \\
2 & $0.2 \%$ GNP & 99.2 & 88.1 & 78.4 & 37 & 24.5 & 21.3 & 20.6 & 19.6 & 10.9 \\
3 & $0.4 \%$ GNP & 99.5 & 88.5 & 80.9 & 31.6 & 15.4 & 12.9 & 12.6 & 12.4 & 11.2 \\
4 & $0.6 \%$ GNP & 99.6 & 89.2 & 80 & 28.9 & 12.9 & 10.3 & 10 & 9.8 & 8.7 \\
5 & $0.8 \%$ GNP & 99.3 & 89.3 & 80 & 29.5 & 14.2 & 11.3 & 11 & 10.7 \\
6 & $1 \%$ GNP & 99.3 & 88.7 & 74.6 & 28.4 & 16.1 & 14.1 & 13.7 & 13.4 & 12.1 \\
7 & $3 \%$ GNP & 98.3 & 87.1 & 76 & 30.1 & 19.7 & 16 & 14.9 & 14 & 9.6 \\
8 & $5 \%$ GNP & 99.2 & 88.6 & 77.9 & 32.3 & 18.5 & 16 & 15.9 & 15.6 & 14.6 \\
\hline
\end{tabular}

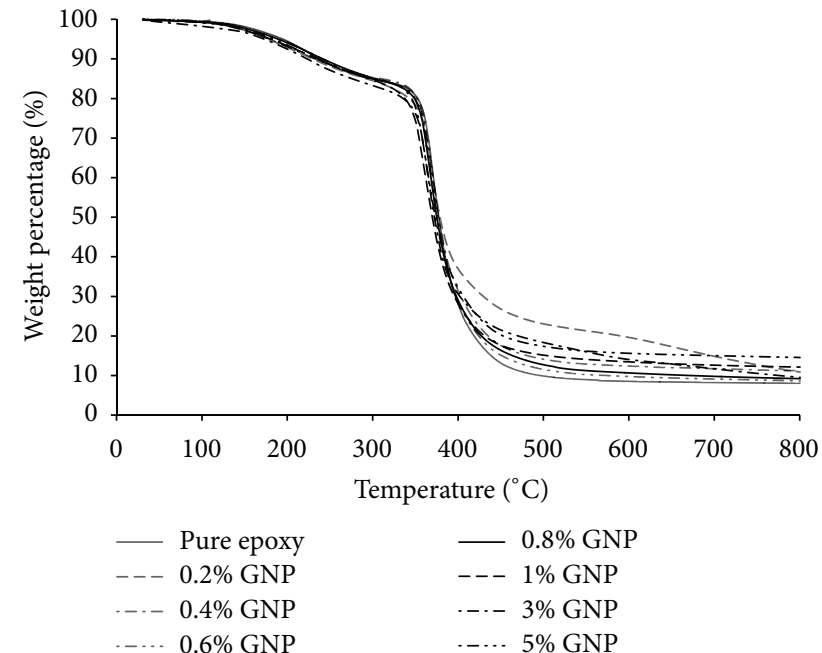

FIGURE 8: TGA thermograms of GNP filled epoxy composites.



FIGURE 9: DTG curves for GNP filled epoxy composites.

of GNP into epoxy resin has shown improvement on the flexural strength and modulus, as well as fracture toughness as compared to pure epoxy, where $0.4 \mathrm{vol} . \%$ achieved highest improvement on the overall mechanical performance. From
SEM characterization, high agglomeration is observed on 1 vol.\% GNP, as compared to lower GNP filler loading (0.4 vol.\%). Poor interface interaction between GNP and epoxy matrix occurred upon the agglomeration, which leads to the deterioration on mechanical performance. However, sudden changes on the bulk electrical conductivity of the composites were measured at 1 vol.\% GNP filler loading, where the conductivity increased by several orders of magnitude, from insulator to semiconductor. Based on the measurement, the percolation threshold of GNP in epoxy is fixed at 1 vol.\%. Before $T_{g}$, the CTE of epoxy is reduced and becomes plateau upon $0.6 \mathrm{vol} . \%$, which is further proven by the increment of $T_{g}$, where increment of crosslink density upon the incorporation of GNP is expected. Despite that, poor thermal stability of the composites is observed. This is due to the poor interfacial interaction between GNP and epoxy matrix upon agglomeration that resulted in high thermal boundary resistance, hence limiting the heat dissipation through the composites. Overall, the optimum concentration of GNP into epoxy is estimated to be at 1 vol.\%, where high improvement on both electrical conductivity and thermal expansion is measured, while mechanical properties outperformed pure epoxy.

\section{Competing Interests}

The authors declare no conflict of interests.

\section{Acknowledgments}

The financial support of Fundamental Research Grant Scheme (FRGS) Grant no. 9003-00472 is gratefully acknowledged.

\section{References}

[1] Y. Zhu, S. Murali, W. Cai et al., "Graphene and graphene oxide: synthesis, properties, and applications," Advanced Materials, vol. 22 , no. 35, pp. 3906-3924, 2010.

[2] O. C. Compton and S. T. Nguyen, "Graphene oxide, highly reduced graphene oxide, and graphene: versatile building blocks for carbon-based materials," Small, vol. 6, no. 6, pp. 711723, 2010. 
[3] D. P. Hansora, N. G. Shimpi, and S. Mishra, "Graphite to graphene via graphene oxide: an overview on synthesis, properties, and applications," JOM, vol. 67, no. 12, pp. 2855-2868, 2015.

[4] S. G. Prolongo, R. Moriche, A. Jiménez-Suárez, M. Sánchez, and A. Ureña, "Advantages and disadvantages of the addition of graphene nanoplatelets to epoxy resins," European Polymer Journal, vol. 61, pp. 206-214, 2014.

[5] J. R. Potts, D. R. Dreyer, C. W. Bielawski, and R. S. Ruoff, "Graphene-based polymer nanocomposites," Polymer, vol. 52, no. 1, pp. 5-25, 2011.

[6] T. K. Das and S. Prusty, "Graphene-based polymer composites and their applications," Polymer-Plastics Technology and Engineering, vol. 52, no. 4, pp. 319-331, 2013.

[7] K. M. F. Shahil and A. A. Balandin, "Thermal properties of graphene and multilayer graphene: applications in thermal interface materials," Solid State Communications, vol. 152, no. 15, pp. 1331-1340, 2012.

[8] C. Lee, X. Wei, J. W. Kysar, and J. Hone, "Measurement of the elastic properties and intrinsic strength of monolayer graphene," Science, vol. 321, no. 5887, pp. 385-388, 2008.

[9] N. Li, Y. Huang, F. Du et al., "Electromagnetic Interference (EMI) shielding of single-walled carbon nanotube epoxy composites," Nano Letters, vol. 6, no. 6, pp. 1141-1145, 2006.

[10] J. Renteria, D. Nika, and A. Balandin, "Graphene thermal properties: applications in thermal management and energy storage," Applied Sciences, vol. 4, no. 4, pp. 525-547, 2014.

[11] E. Pop, V. Varshney, and A. K. Roy, "Thermal properties of graphene: fundamentals and applications," MRS Bulletin, vol. 37, no. 12, pp. 1273-1281, 2012.

[12] J. J. Licari and D. W. Swanson, Adhesives Technology for Electronic Applications-Materials, Processing, Reliability, Elsevier, San Diego, Calif, USA, 2nd edition, 2011.

[13] M. Mandhakini, A. Chandramohan, K. Jayanthi, and M. Alagar, "Carbon black reinforced C8 ether linked bismaleimide toughened electrically conducting epoxy nanocomposites," Materials \& Design, vol. 64, pp. 706-713, 2014.

[14] G. A. H. Oxfall, T. Gkourmpis, R. W. Rychwalski, and M. Rigdahl, "Effect of carbon black on electrical and rheological properties of graphite nanoplatelets/poly(ethylene-butyl acrylate) composites," Express Polymer Letters, vol. 9, no. 1, pp. 6676, 2015.

[15] H. P. Wu, X. J. Wu, M. Y. Ge, G. Q. Zhang, Y. W. Wang, and J. Z. Jiang, "Effect analysis of filler sizes on percolation threshold of isotropical conductive adhesives," Composites Science and Technology, vol. 67, no. 6, pp. 1116-1120, 2007.

[16] H. Suherman, J. Sahari, and A. B. Sulong, "Effect of small-sized conductive filler on the properties of an epoxy composite for a bipolar plate in a PEMFC," Ceramics International, vol. 39, no. 6, pp. 7159-7166, 2013.

[17] S.-Y. Fu, X.-Q. Feng, B. Lauke, and Y.-W. Mai, "Effects of particle size, particle/matrix interface adhesion and particle loading on mechanical properties of particulate-polymer composites," Composites Part B: Engineering, vol. 39, no. 6, pp. 933-961, 2008.

[18] J. González-Benito, E. Castillo, and J. F. Caldito, "Coefficient of thermal expansion of $\mathrm{TiO}_{2}$ filled EVA based nanocomposites. A new insight about the influence of filler particle size in composites," European Polymer Journal, vol. 49, no. 7, pp. 17471752, 2013.

[19] Y. Liu, X. Li, W. Guo, Q. Li, and C. Wu, "Effect of dispersion of carbon black on electrical and thermal properties of poly(ethylene terephthalate)/carbon black composites," Journal of Macromolecular Science, Part B: Physics, vol. 48, no. 1, pp. 146156, 2009.

[20] P. Xu and Z.-Y. Li, "Effect of particle shape on the effective dielectric response of nanocomposite close to the percolation threshold," Physica B: Condensed Matter, vol. 348, no. 1-4, pp. 101-107, 2004.

[21] V. Kushvaha and H. Tippur, "Effect of filler shape, volume fraction and loading rate on dynamic fracture behavior of glassfilled epoxy," Composites Part B: Engineering, vol. 64, pp. 126$137,2014$.

[22] Y. Wang, J. Yu, W. Dai et al., "Enhanced thermal and electrical properties of epoxy composites reinforced with graphene nanoplatelets," Polymer Composites, vol. 36, no. 3, pp. 556-565, 2015.

[23] V. Goyal and A. A. Balandin, "Thermal properties of the hybrid graphene-metal nano-micro-composites: applications in thermal interface materials," Applied Physics Letters, vol. 100, no. 7, Article ID 073113, 2012.

[24] P. Goli, S. Legedza, A. Dhar, R. Salgado, J. Renteria, and A. A. Balandin, "Graphene-enhanced hybrid phase change materials for thermal management of Li-ion batteries," Journal of Power Sources, vol. 248, pp. 37-43, 2014.

[25] J. Renteria, S. Legedza, R. Salgado et al., "Magneticallyfunctionalized self-aligning graphene fillers for high-efficiency thermal management applications," Materials \& Design, vol. 88, pp. 214-221, 2015.

[26] E. E. Tkalya, M. Ghislandi, G. de With, and C. E. Koning, "The use of surfactants for dispersing carbon nanotubes and graphene to make conductive nanocomposites," Current Opinion in Colloid and Interface Science, vol. 17, no. 4, pp. 225-232, 2012.

[27] Z. A. Ghaleb, M. Mariatti, and Z. M. Ariff, "Properties of graphene nanopowder and multi-walled carbon nanotubefilled epoxy thin-film nanocomposites for electronic applications: the effect of sonication time and filler loading," Composites Part A: Applied Science and Manufacturing, vol. 58, pp. 7783, 2014.

[28] S. Chandrasekaran, C. Seidel, and K. Schulte, "Preparation and characterization of graphite nano-platelet (GNP)/epoxy nano-composite: mechanical, electrical and thermal properties," European Polymer Journal, vol. 49, no. 12, pp. 3878-3888, 2013.

[29] M. Monti, M. Rallini, D. Puglia, L. Peponi, L. Torre, and J. M. Kenny, "Morphology and electrical properties of grapheneepoxy nanocomposites obtained by different solvent assisted processing methods," Composites Part A: Applied Science and Manufacturing, vol. 46, no. 1, pp. 166-172, 2013.

[30] A. Allaoui and N. El Bounia, "How carbon nanotubes affect the cure kinetics and glass transition temperature of their epoxy composites?-a review," Express Polymer Letters, vol. 3, no. 9, pp. 588-594, 2009. 

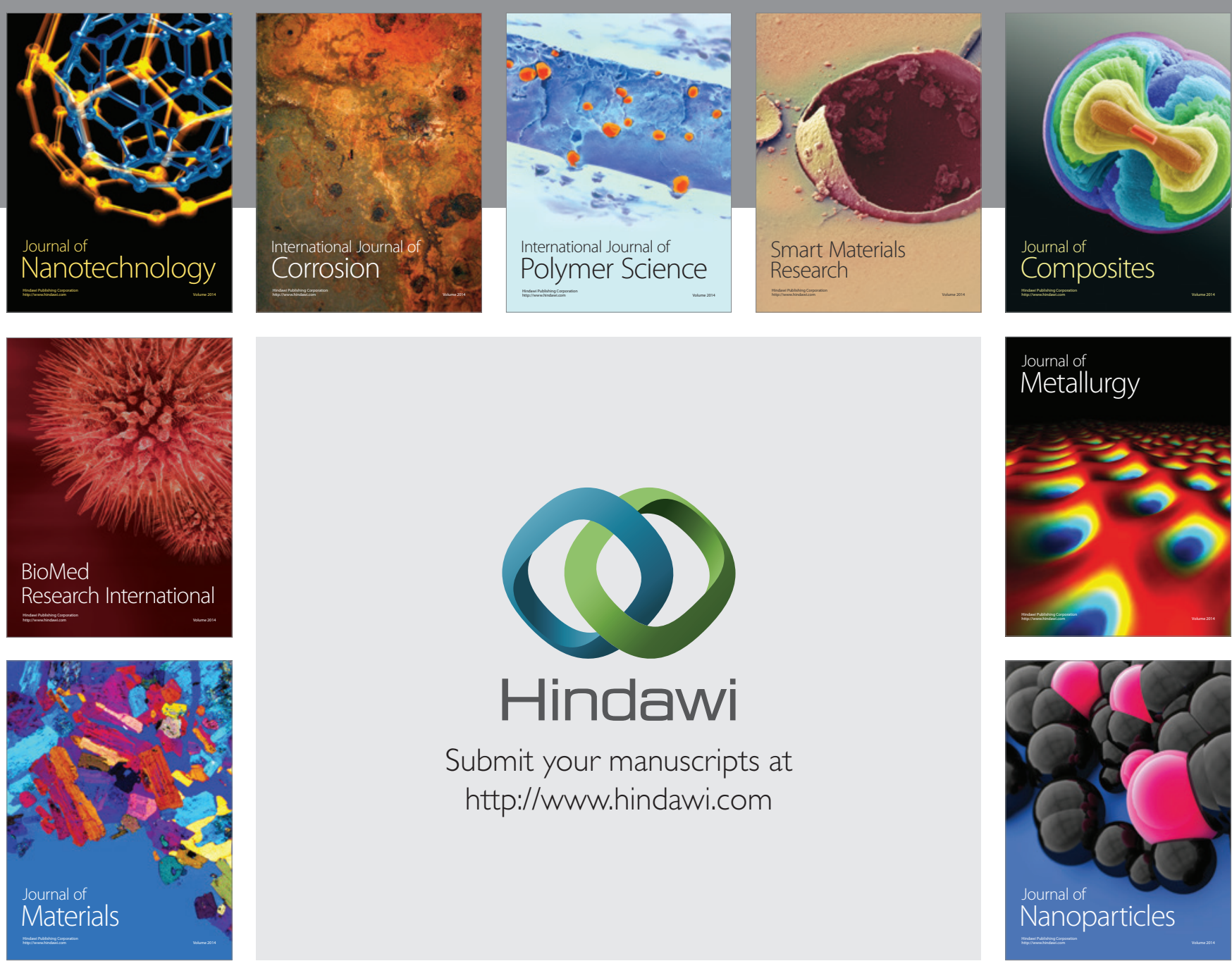

\section{Hindawi}

Submit your manuscripts at

http://www.hindawi.com

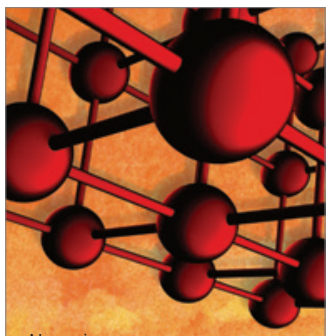

Materials Science and Engineering

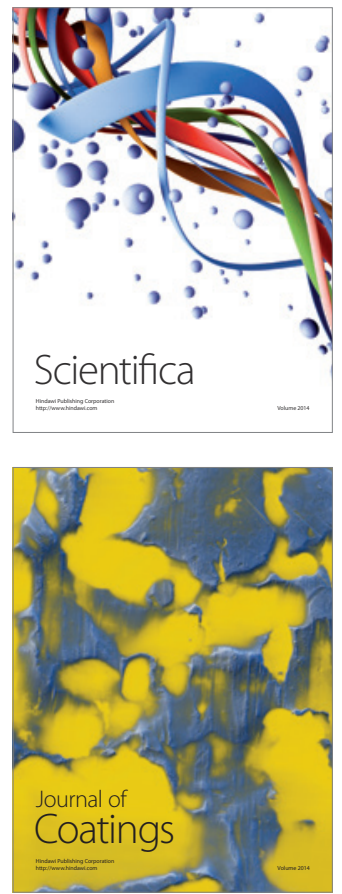
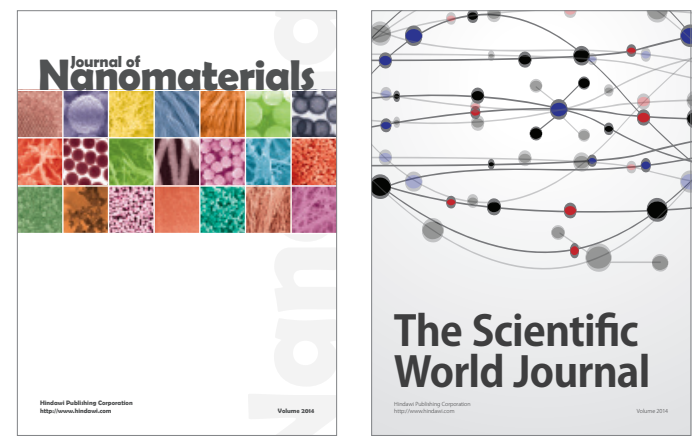

The Scientific World Journal
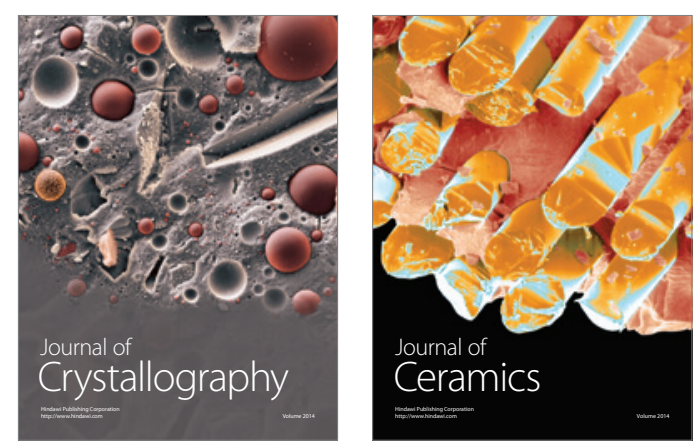
